\title{
GCU
}

Glasgow Caledonian

University

University for the Common Good

\section{Numerical computation of electric field and potential along silicone rubber insulators under contaminated and dry band conditions}

Arshad; Nekahi, A.; McMeekin, S.G.; Farzaneh, M.

Published in:

3D Research

DOI:

$10.1007 / \mathrm{s} 13319-016-0101-\mathrm{z}$

Publication date:

2016

Document Version

Author accepted manuscript

Link to publication in ResearchOnline

Citation for published version (Harvard):

Arshad, , Nekahi, A, McMeekin, SG \& Farzaneh, M 2016, 'Numerical computation of electric field and potential along silicone rubber insulators under contaminated and dry band conditions', 3D Research, vol. 7, no. 25, 25. https://doi.org/10.1007/s13319-016-0101-z

\section{General rights}

Copyright and moral rights for the publications made accessible in the public portal are retained by the authors and/or other copyright owners and it is a condition of accessing publications that users recognise and abide by the legal requirements associated with these rights.

Take down policy

If you believe that this document breaches copyright please view our takedown policy at https://edshare.gcu.ac.uk/id/eprint/5179 for details of how to contact us. 


\title{
Numerical Computation of Electric Field and Potential along Silicone Rubber Insulators under Contaminated and Dry Band Conditions
}

\author{
Arshad · A. Nekahi · S. G. McMeekin · M. Farzaneh
}

Received: date / Accepted: date

\begin{abstract}
Electrical field distribution along the insulator surface is considered one of the important parameters for the performance evaluation of outdoor insulators. In this paper numerical simulations were carried out to investigate the electric field and potential distribution along silicone rubber insulators under various polluted and dry band conditions. Simulations were performed using commercially available simulation package Comsol Multiphysics based on the Finite Element Method (FEM). Various pollution severity levels were simulated by changing the conductivity of pollution layer. Dry bands of $2 \mathrm{~cm}$ width were inserted at the high voltage end, ground end, middle part, shed, sheath, and at the junction of shed and sheath to investigate the effect of dry band location and width on electric field and potential distribution. Partial pollution conditions were simulated by applying pollution layer on the top and bottom surface respectively. It was observed from the simulation results that electric field intensity was higher at the metal electrode ends and at the junction of dry bands. Simulation results showed that potential distribution is nonlinear in the case of clean and partially polluted insulator and linear for uniform pol-
\end{abstract}

Arshad

School of Engineering and Built Environment, Glasgow Caledonian University, G4 0BA, UK.

E-mail: Arshad@gcu.ac.uk

\section{A. Nekahi}

School of Engineering and Built Environment, Glasgow Caledonian University, G4 0BA, UK.

S. G. McMeekin

School of Engineering and Built Environment, Glasgow Caledonian University, G4 0BA, UK.

\section{Farzaneh}

Canada Research Chair on Atmospheric Icing Engineering of Power Networks (INGIVRE) www.cigele.ca, Universit du Qubec Chicoutimi, QC, Canada lution layer. Dry band formation effect both potential and electric field distribution. Power dissipated along the insulator surface and the resultant heat generation was also studied. The results of this study could be useful in the selection of polymeric insulators for contaminated environments.

Keywords polymer insulator · pollution - electric field · dry band $\cdot$ potential distribution $\cdot$ power dissipation

\section{Introduction}

During service conditions outdoor insulators have to withstand various types of electrical, mechanical and environmental stresses. For reliable transmission of power, performance of outdoor insulators under contaminated and polluted conditions is of prime importance. Outdoor insulators need to withstand all the electrical, mechanical and environmental stresses during service conditions. During the past few decades, different types of polymeric materials have been developed. Polymeric insulators are replacing porcelain and glass insulators in transmission and distribution industry due to their hydrophobic nature [1]. Previous research indicates that polymeric materials are vulnerable to local stresses due to their organic nature $[1,2,3]$. Different environmental conditions e.g. UV radiation, rain, wind, humidity, temperature and air pollution contribute to the erosion and degradation of polymer insulators [4]. Pollution deposition on the insulator surface in combination with moist conditions lead to partial discharges on the insulator surface and possibly flashover. Due to the weaker chemical bonding between polymeric molecules as compared to porcelain and glass, they are more susceptible to chemical changes due to corona, partial discharges and flashovers [5].

During rain or cold fog, the presence of discrete water droplets on the polymer insulator surface increase the electric field intensity and resulting in corona and partial discharges [6]. 
Surface corona and partial discharges result in insulator ageing and loss of hydrophobicity. The electric field intensification and ageing of polymer insulator due to water droplets has been investigated by many researchers in the past $[7,8,9$, 10]. The loss of surface hydrophobicity encourages the formation of continuous pollution layer on the insulator. Pollution deposition along the insulator surface is not uniform and depends on various factors e.g. wind velocity and direction, distance from shore line, geographical location etc. The non-uniform pollution deposition leads to non-linear current density and subsequently non-linear electric field distribution along the insulator surface. The high electric field stress at certain areas of insulator surface leads to dry band formations, surface discharges and under certain conditions flashover [11]. Electric field distribution along a uniformly polluted polymeric insulator was studied in [12]. Effect of pollution severity on electric field distribution was studied and concluded that electric field intensity increases with increase in pollution severity. The presence of dry band along the insulator surface and its effect on the electric field distribution has been discussed in [13]. The study of electric field distribution along polymeric insulators is very important for understanding the discharge mechanism and pollution flashover. Moreover, electric field study gives an indication of the possible damage and service life of insulator under contaminated conditions $[14,15]$. Electric field measurement could also be used as a diagnostic tool to detect invisible defects in polymer insulators. These internal defects usually occur at the interface of Fibre Reinforced Plastic (FRP) core and polymer weather sheds. Electric discharges at these points due to high electric field burns the fibres and weaken the mechanical strength of FRP core $[16,17]$. Although electric field and potential distribution along polluted insulator has been studied by many researchers, very little knowledge exist about the effect of dry band location and partial pollution on electric field distribution. The major cause of dry band formation is the power dissipation along the insulator surface due to the flow of leakage current. To the best of our knowledge, no numerical study exists to define the threshold value of power dissipation for dry band formation.

In this paper electric field and potential distribution along a standard $33 \mathrm{kV}$ polymeric insulator has been studied first for clean insulator and then under various contaminated conditions. A commercial simulation package Comsol Multiphysics is used for simulations based on finite element method. The electrostatic formulation of AC/DC physics was used for all simulations. Effect of pollution severity, pollution layer thickness, dry band width and location on the electric field and potential distribution has been studied in detail. The non-uniformity of pollution layer in service conditions has been investigated by implying various combinations of nonuniform pollution on shed and core regions.

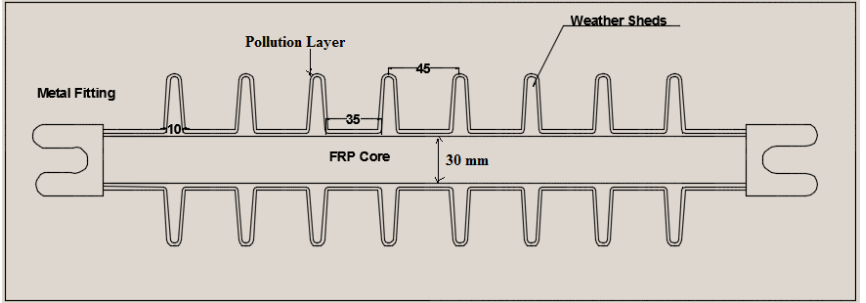

Fig. 1: Regular shed polymeric insulator.

Table 1: Insulator and Simulation Parameters.

\begin{tabular}{|l|l|}
\hline No. of Sheds & 8 \\
\hline Leakage Distance & $900 \mathrm{~mm}$ \\
\hline Shed Diameter & $105 \mathrm{~mm}$ \\
\hline Sheath Diameter & $30 \mathrm{~mm}$ \\
\hline Shed Spacing & $35 \mathrm{~mm}$ \\
\hline SIR Relative permittivity & 4.3 \\
\hline FRP Relative permittivity & 7.2 \\
\hline Relative permittivity of water & 81 \\
\hline Relative permittivity of air & 1 \\
\hline
\end{tabular}

\section{Simulation method}

A standard $33 \mathrm{kV}$ silicone rubber insulator was used for simulation. The insulator consists of a fibre reinforced plastic rod as a load bearing structure, silicone rubber as weather shed material and copper end fittings and shown in Figure 1. The insulator and material properties are given in Table 1. Partial differential equations based on Maxwells equation and finite element method was used for simulations. Surface of insulator is divided into large numbers of non-overlapping sub-domains called finite elements $[18,19]$.

These finite elements can be of any shape depending on the overall geometry but triangular elements were chosen for this specific case. This division into finite elements makes the calculation simple and easy and results in the global solution of the whole system. To minimize the processing time and complexity a 2D geometry of silicone rubber insulator is considered in this paper. Very large number of finite elements can improve the accuracy but also increase the processing time and a trade-off between accuracy and computational time has to be made. Figure 2 shows a meshed model of the insulator intended for simulation. Meshing was applied manually to the geometry so that more refined meshes can be applied to the region of interests for improved accuracy. An air boundary is considered around the insulator model so that the effect of external forces on electric field and potential distribution can be minimized. The pollution layer along the insulator surface was modelled as a conductive water layer and conductivity of water layer was changed 


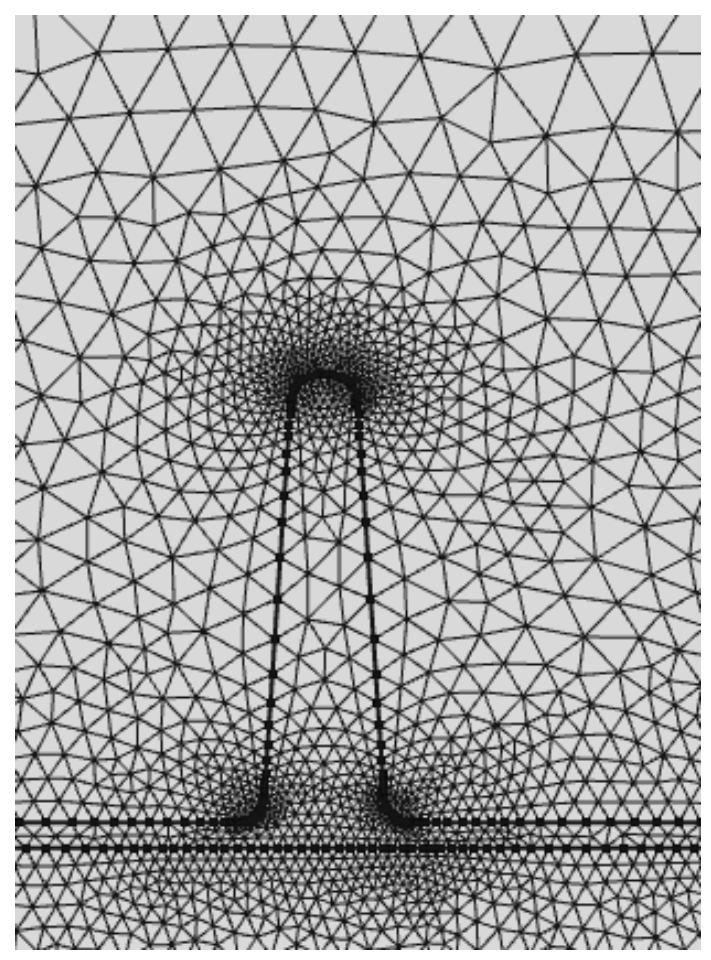

Fig. 2: Meshed model of the polymeric insulator.

to simulate the effect of pollution severity level. Electric field along the insulator surface can be calculated directly from the potential distribution by subtracting the potential gradient from it [20].

$E=-\nabla V$

Maxwells equation could be used to calculate the change in electric field:

$\nabla E=\frac{\rho}{\varepsilon}$

Where and are the resistivity and dielectric constants of material respectively. Equation (1) and (2) can be combined to obtain the Poissons equation [21].

$-\nabla(\nabla E)=\frac{\rho}{\varepsilon}$

Poissons equation will become a Laplace equation if there is no space charge present:

$\varepsilon \nabla(\nabla E)=0$

\section{Sample configurations}

A standard $33 \mathrm{kV}$ polymeric insulator shown in Figure 1 was used for simulation. A total of 8 configurations were tested as shown in Figure 3 (a)-(h). For simplicity, certain portions of insulator specifying the pollution layer and dry band location are shown in Figure 3. Clean insulator is used as a reference point for all other cases so that a relation can be established between electric field, potential and the corresponding pollution condition.

\section{Results and discussions}

\subsection{Clean insulator}

Electric field and potential distribution in the case of a clean, $33 \mathrm{kV}$ polymeric insulators are shown in Figure 4. In the case of clean insulator, very little current known as displacement current is flowing through the surface. The electric field distribution along clean insulator is capacitive in nature due to the flow of displacement current. The potential distribution for a clean and dry insulator is dependent on the self-capacitance of the insulator surface and any added stray capacitance. The threshold value of electric field intensity for corona initiation along clean insulator surface was investigated experimentally in [22] and found out to be 22.8 $\mathrm{kV} / \mathrm{cm}$. The results of Figure 4 show that, electric field intensity is maximum at the electrode junction and symmetrical around the insulator. Potential distribution is non-linear due to the capacitive behaviour of clean insulator surface. The line graph of Figure 5 shows the non-linearity of potential distribution. Figure 6 shows that electric field intensity is high at metal electrodes and at the junction of shed and sheath region.

\subsection{Uniform pollution}

Potential distribution along a uniformly polluted insulator is shown in Figure 7. Pollution layer conductivity was varied to simulate light, medium, heavy and very heavy pollution. In the case of uniform pollution layer, potential distribution was affected by pollution severity level. As the pollution conductivity was increased, conduction current along the surface changes and affect the potential distribution. For a very heavy pollution severity level, potential distribution is linear while for light pollution potential distribution has negligible changes as compared to clean insulator.

Electric field intensity at the electrode junction decrease with increase in pollution severity and a near to uniform electric field distribution was observed. Electric field intensity increased with increase in pollution conductivity and highest electric field stress was observed in the case of very heavy pollution shown in Figure 8. The electric field stress near the junction of shed and sheath region was found to be high as compared to other locations. This might be due to the small radius of curvature of the junction regions. Minimum 


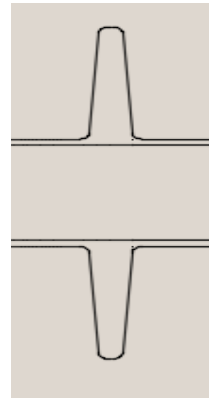

(a) clean insulator

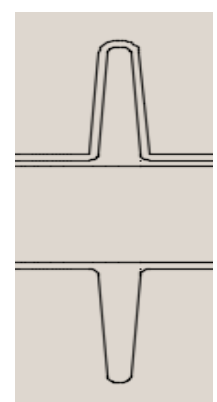

(c) top pollution

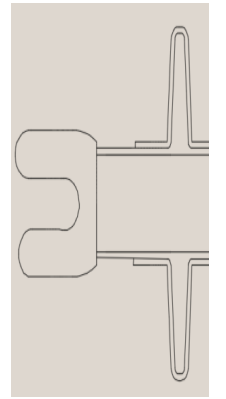

(e) energized end dry band
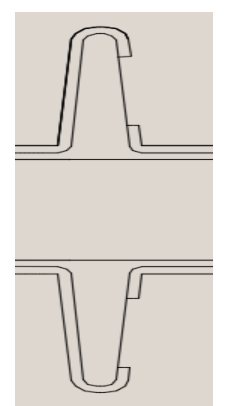

(g) shed dry band

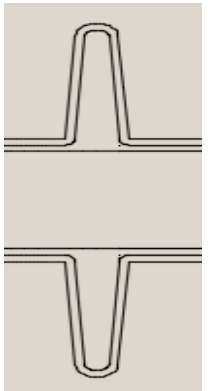

(b) uniform pollution layer

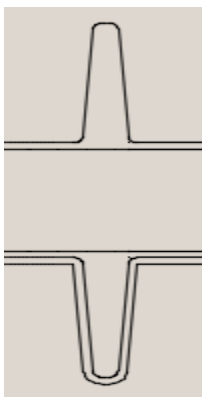

(d) bottom pollution

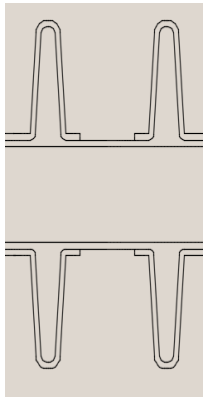

(f) core dry band

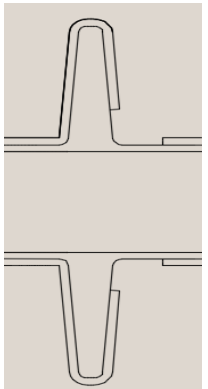

(h) junction dry band

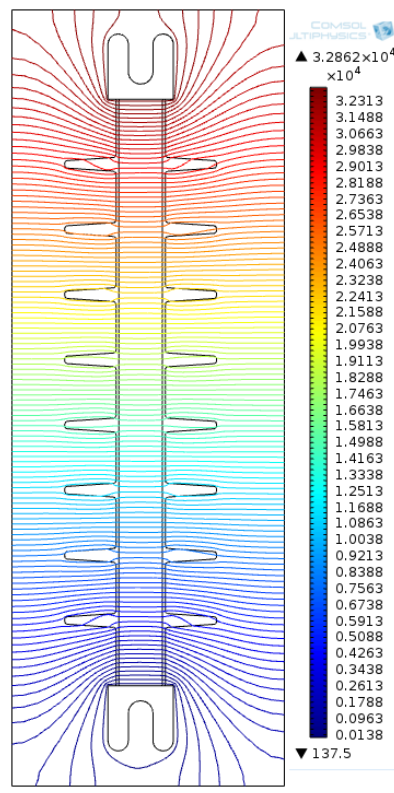

(a) potential distribution

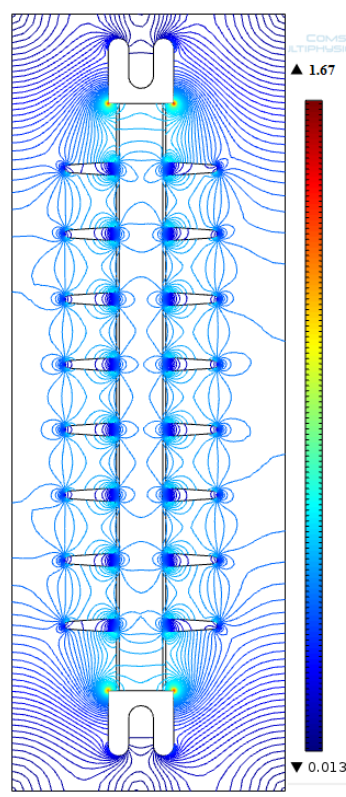

(b) electric field distribution
Fig. 4: Contour plot of clean insulator

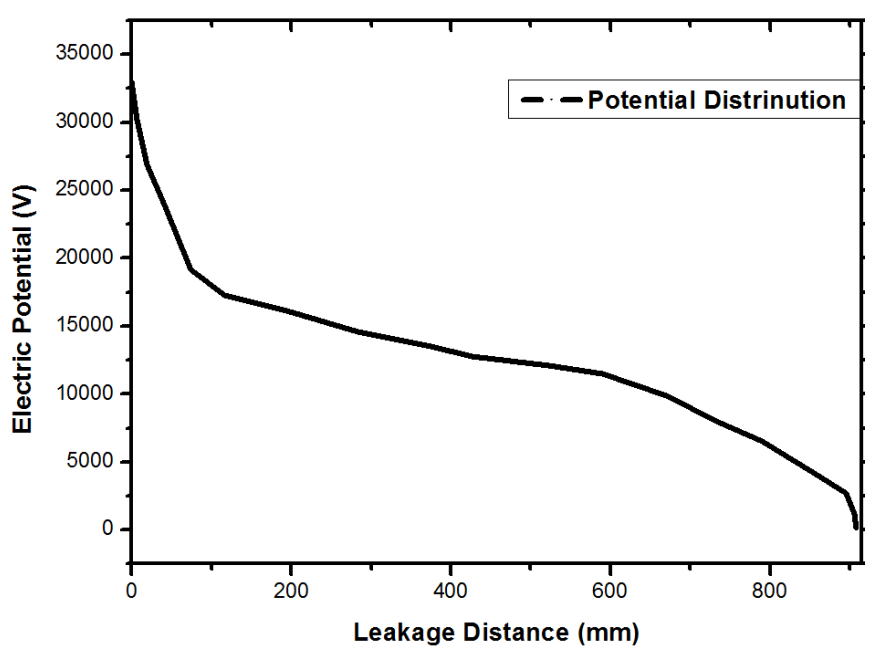

Fig. 5: Line graph of potential distribution along a clean insulator.

electric field stress was observed at the tip of shed region as shown in Figure 9.

\subsection{Partial pollution}

Pollution distribution on real insulators may not be uniform as studied in section 4.2. Pollution deposition on practical insulators depends on insulator orientation, geometry, rain, wind speed and direction etc. The top surface of a horizontally located insulator may be less polluted as compared to 


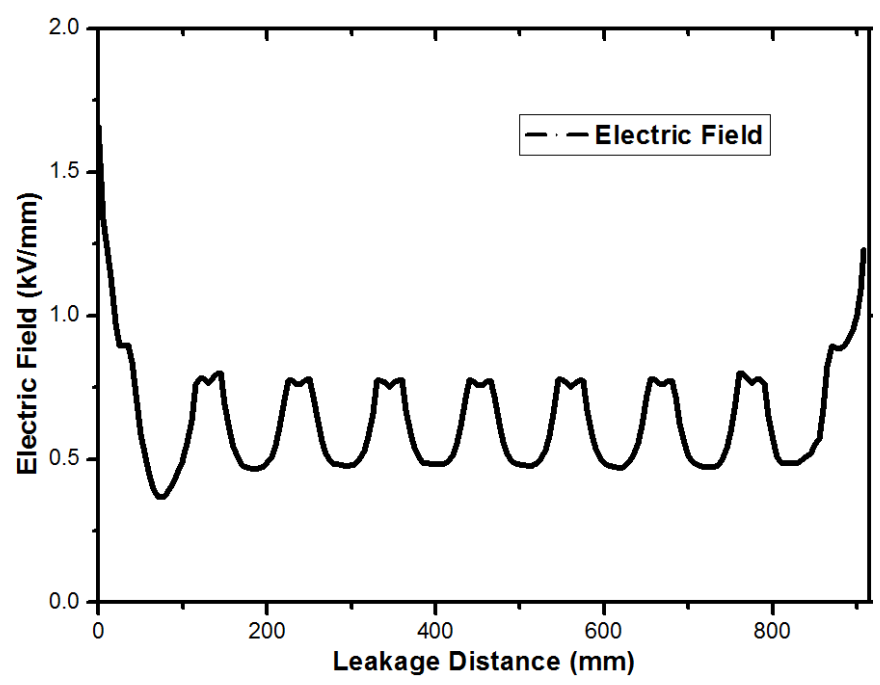

Fig. 6: Line graph of electric field distribution along a clean insulator.

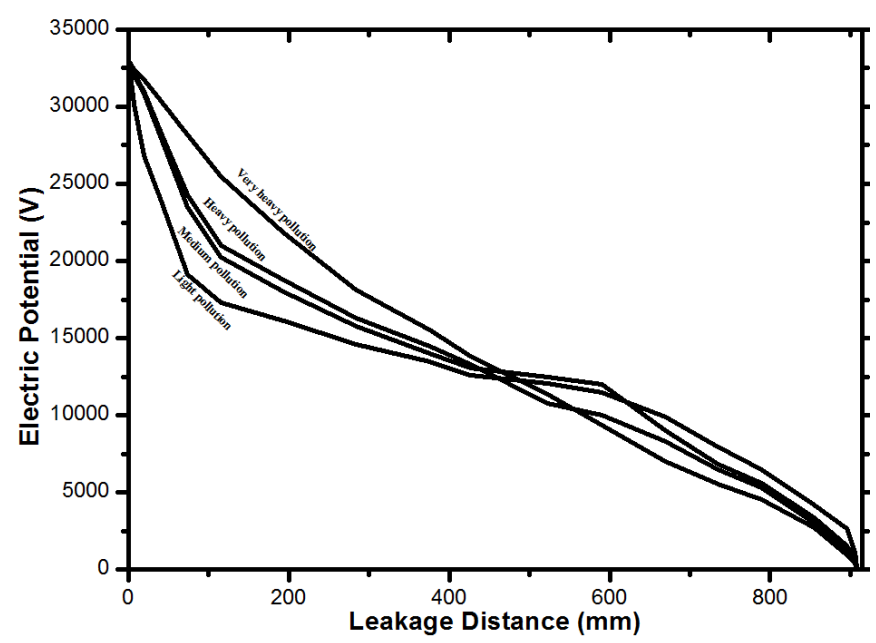

Fig. 7: Line graph of potential distribution along a uniformly polluted insulator.

bottom surface due to wind and rain. The same may be true for bottom surface due to wind direction and insulator geometry. This phenomenon was investigated by applying the pollution layer on top and bottom surface independently and electric field and potential distribution were calculated. As can be seen in Figure 10 potential distribution for partially polluted insulator is non-linear as compared to uniform pollution where potential distribution becomes linear when the pollution conductivity increased. Electric field distribution was found to be non-linear as compared to uniform pollution layer.

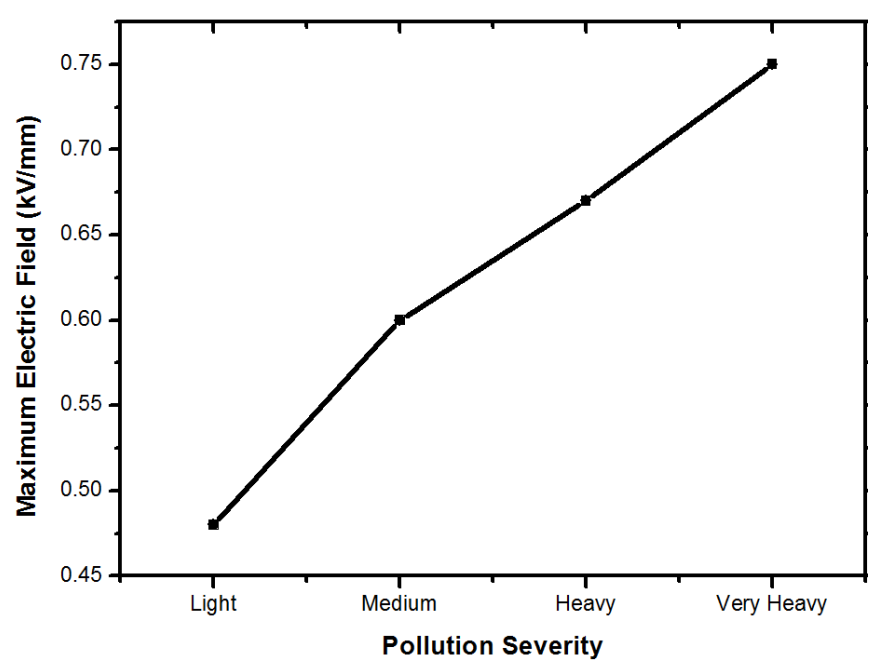

Fig. 8: Electric field intensity at different pollution severity.

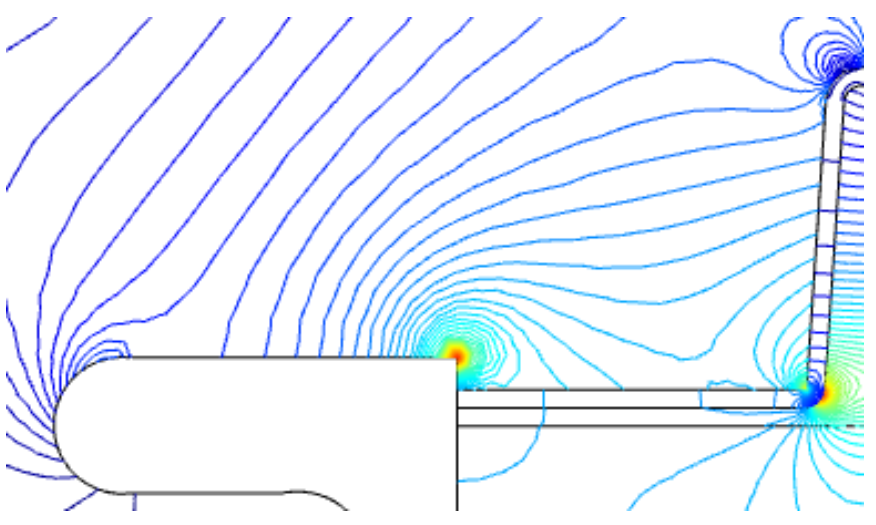

Fig. 9: Electric field distribution at electrode end, shed and core junction and at the tip of shed region.

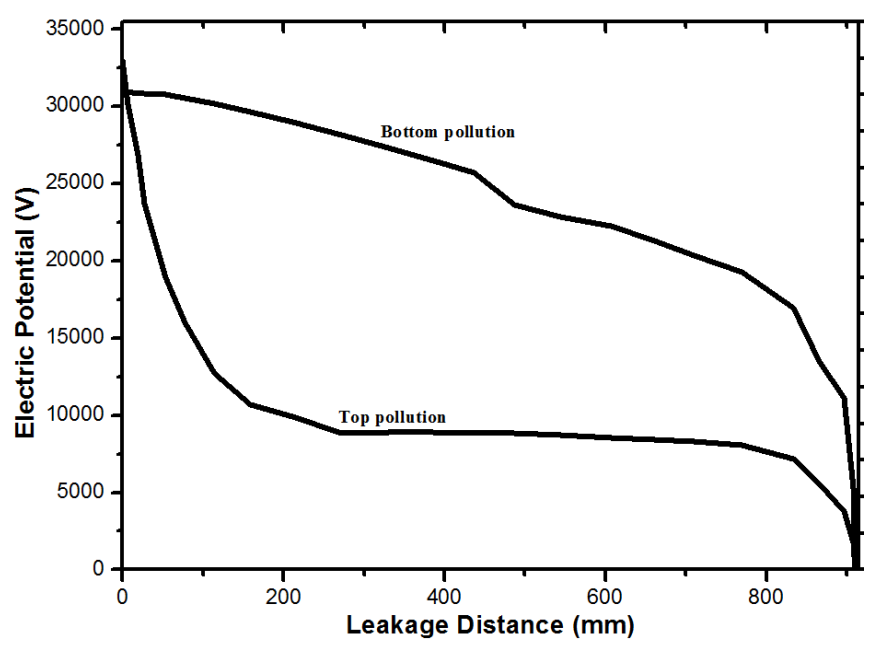

Fig. 10: Potential distribution along partially polluted insulator. 


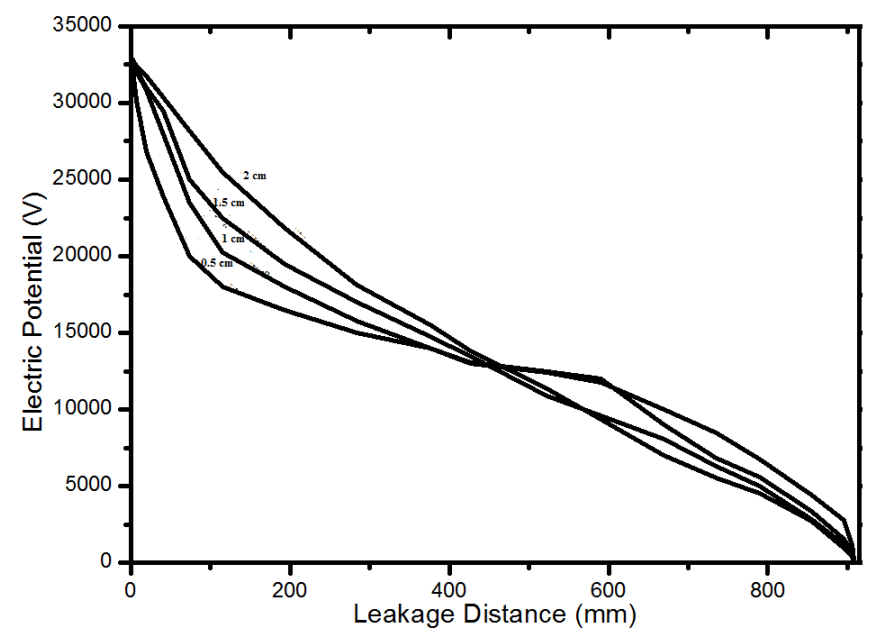

Fig. 11: Potential distribution for various pollution layer thickness.

\subsection{Pollution layer thickness}

As mentioned above, pollution distribution along the insulator surface is not uniform. Pollution layer thickness along the surface may change due to various conditions. Pollution layer thickness was varied from $0.5 \mathrm{~cm}$ to $2.0 \mathrm{~cm}$ in steps of $0.5 \mathrm{~cm}$ to study the effect of pollution layer thickness on electric field and potential distribution. Medium pollution severity was chosen for this simulation. Figure 11 shows the potential distribution for various pollution layer thicknesses. For 0.5 and $1.0 \mathrm{~cm}$ pollution layer thickness, the potential distribution was non-linear but for $2.0 \mathrm{~cm}$, pollution distribution was found to be linear. Electric field intensity increased with increase in pollution layer thickness. The effect of increase in pollution conductivity and layer thickness on electric field intensity was found to be identical. Electric field distribution for various layer thicknesses is shown in Figure 12.

\subsection{Dry band modeling}

Dry bands formation along the surface of outdoor insulators is a very important phenomenon. It has been investigated in literature that the flashover performance of outdoor insulators is greatly influenced by the formation of dry bands [23, 24,25]. Electric field enhancements due to dry band formation have also been investigated in [26]. The previous literature does not consider the location of dry bands and it is assumed that dry band forms near the high voltage electrode of insulator due to the high electric field stress at that location. Although this assumption might be true in certain conditions, but dry band formation is also influenced by pollution distribution, power dissipation and the resultant Joule heating along the insulator surface. Six dry band locations

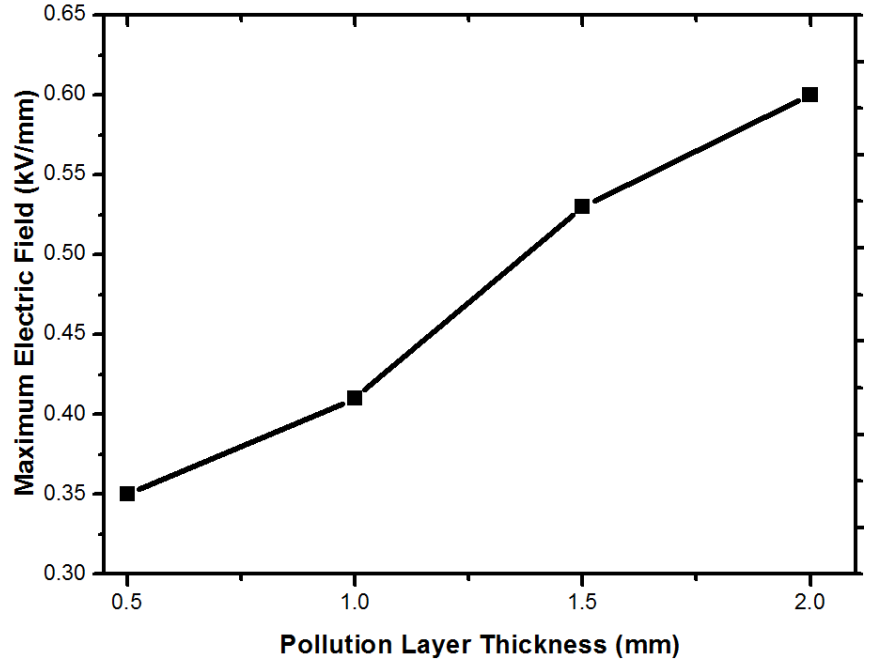

Fig. 12: Electric field at different pollution layer thickness.

were considered in this section; dry band at high voltage end, ground end, middle part, shed region, sheath region and junction of shed and sheath region. Potential distribution was found to be non-linear in all cases and the highest voltage drop occurred across the dry band along the insulator surface. Electric field distribution for a dry band at ground end was found to be similar to that of dry band at high voltage end, and therefore was not reported here. Similarly, the dry band at middle part has the same effect as of sheath dry band. Figure 13 shows the electric field distribution for different dry band location.

\section{Heat generations along the insulator surface}

Dry band forms along the insulator surface due to non-uniform pollution distribution. Leakage current is driven along the insulator surface due to the applied electric stress. Due to Joule heating, the flow of current through a conducting pollution layer will generate heat and resulting in dry band formation. The width of dry band depends on the amount of heat generated at certain location along the surface. Furthermore, electric field distribution is also effected by the amount of heat generated [26]. The heat generation also starts chemical degradation due to the dielectric loss of the insulating material resulting in ageing and breakdown. Heat generated along a standard $33 \mathrm{kV}$ silicone rubber insulator is investigated in this paper with various pollution severity and dry band conditions. Mathematically heat generated along a solid dielectric under AC voltages can be calculated using the following relation [26].

$H_{\text {gen }}=\frac{E^{2} f \varepsilon_{r} \tan (\rho)}{1.8 \times 10^{12}}$ 


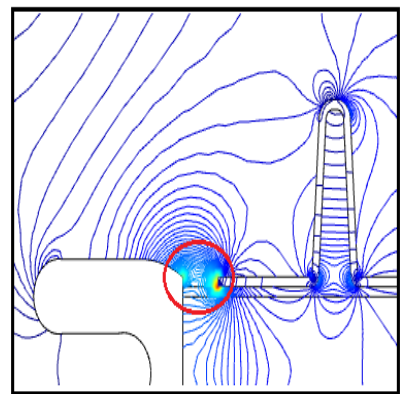

(a) dry band at high voltage end

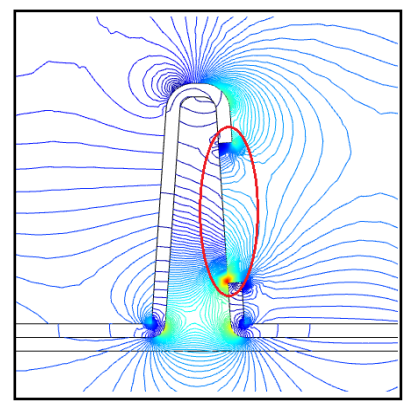

(c) dry band at shed

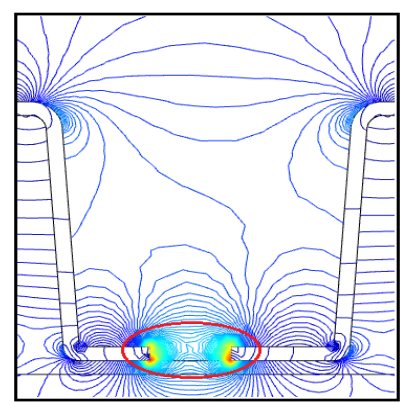

(b) dry band at core

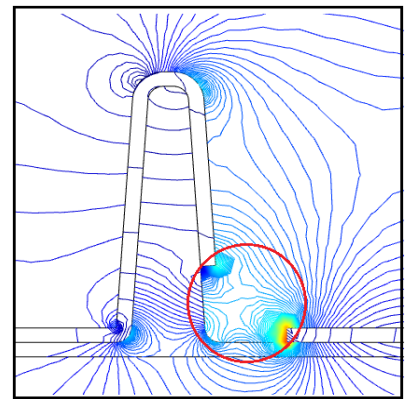

(d) dry band at junction
Fig. 13: Electric field distribution for variousdry band locations

$\tan (\rho)$ and $\varepsilon_{r}$ are the loss tangent and relative permittivity of silicone rubber. $E$ is the maximum electric field stress along the insulator surface and $f$ is the power frequency.

\section{Power dissipations in pollution layer}

Power is dissipated along the insulator surface due to the flow of leakage current along the insulator surface. The amount of power dissipated at any point along the insulator depends on the pollution density and subsequently leakage current density. Power dissipation results in joule heating and dry band formation along the surface. Mathematically, power dissipated at any specific location will depend on the surface resistance and leakage current.

$P=I^{2} R$

Where $R$ is dependent on the pollution layer thickness $t$, length and pollution layer conductivity $\rho$.

$R=\frac{l}{\rho A}$

$A=2 \pi r t$
The current density in the pollution layer can be expressed as:

$J=\frac{I}{A}$

$J=\rho E$

Where $E$ is the electric field intensity at any point along the insulator surface. By replacing the eq. (6) and (8) in (5) we obtained the following relation.

$P=2 \pi r l \rho E^{2}$

Using eq. (10) the dissipated power in the pollution layer per unit area and per unit volume can be calculated.

$P_{A}=t \rho E^{2}$

$P_{V}=\rho E^{2}$

The above equation can be used to calculate the power dissipated in a polluted outdoor insulator and predict the dry band formation based on the power dissipation.

\section{Conclusion}

Numerical simulations of electrical field and potential distribution were carried out to study the effects of various parameters. It was found out that potential distribution is more effected by pollution severity, conductivity and location. Pollution distribution becomes uniform with increase in severity and conductivity. Electric field distribution was much more effected by dry band formation rather than pollution severity and conductivity. For uniform pollution electric field intensity at electrode ends and at the junction of shed and sheath region was found to be very high as compared to other parts of the insulator surface. In the case of dry bands, all voltage drops occurs along the dry bands and electric field intensity was found to be high at the edges of dry bands. This high electric field intensity at the edges of dry bands facilitates partial arcs and under certain conditions may lead to flashovers. These partial arcs also result in ageing and degradation of insulator surface due to their organic nature. These results could be used for the diagnostic of polymer insulator used in wet and polluted environments. The results presented here are the preliminary work and it is intended to perform experiment to support these numerical results. 


\section{References}

1. J. Verdu, Oxydative Ageing of Polymers. John Wiley \& Sons, 2012.

2. M. Amin, M. Akbar, and M. N. Khan, "Aging investigations of polymeric insulators: Overview and bibliography," Electrical Insulation Magazine, IEEE, vol. 23, no. 4, pp. 44-50, 2007.

3. D. L. Allara, "Aging of polymers," Environmental health perspectives, vol. 11, p. 29, 1975.

4. T. Sörqvist and A. E. Vlastós, "Performance and ageing of polymeric insulators," Power Delivery, IEEE Transactions on, vol. 12, no. 4, pp. 1657-1665, 1997.

5. W. Que and S. A. Sebo, "Typical cases of electric field and voltage distribution calculations along polymer insulators under various wet surface conditions," in Electrical Insulation and Dielectric Phenomena, 2002 Annual Report Conference on, pp. 840-843, IEEE, 2002.

6. I. A. Joneidi, M. A. Kamarposhti, A. A. S. Akmal, and H. Mohseni, "Leakage current analysis, fft calculation and electric field distribution under water droplet on polluted silicon rubber insulator," Electrical Engineering, vol. 95, no. 4, pp. 315-323, 2013.

7. K. Katada, Y. Takada, M. Takano, T. Nakanishi, Y. Hayashi, and R. Matsuoka, "Corona discharge characteristics of water droplets on hydrophobic polymer insulator surface," in Properties and Applications of Dielectric Materials, 2000. Proceedings of the 6th International Conference on, vol. 2, pp. 781-784, IEEE, 2000.

8. A. Phillips, D. Childs, and H. Schneider, "Aging of nonceramic insulators due to corona from water drops," Power Delivery, IEEE Transactions on, vol. 14, no. 3, pp. 1081-1089, 1999.

9. R. Anbarasan and S. Usa, "Electrical field computation of polymeric insulator using reduced dimension modeling," Dielectrics and Electrical Insulation, IEEE Transactions on, vol. 22, no. 2, pp. 739-746, 2015.

10. G. Haddad, K. Wong, and R. Gupta, "Dielectric breakdown characteristics of htv silicone rubber under multiple stress conditions," in Electrical Insulating Materials (ISEIM), Proceedings of 2014 International Symposium on, pp. 276-279, IEEE, 2014.

11. M. Albano, A. Haddad, H. Griffiths, R. Waters, Y. Hicks, and R. Sarathi, "Dry-band and discharge activity characterization using visual and ir data analysis," in High Voltage Engineering and Application (ICHVE), 2014 International Conference on, pp. 1-4, IEEE, 2014.

12. A. Arshad, Nekahi, S. McMeekin, M. Farzaneh, et al. "Effect of pollution severity on electric field distribution along a polymeric insulator," in Properties and Applications of Dielectric Materials (ICPADM), 2015 IEEE 11th International Conference on the, pp. 612-615, IEEE, 2015.

13. Arshad, A. Nekahi, S. McMeekin, M. Farzaneh, et al., "Effect of dry band location on electric field distribution along a polymeric insulator under contaminated conditions," in Power Engineering Conference (UPEC), 2015 50th International Universities, pp. 14, IEEE, 2015

14. A. Tzimas, C. Zachariades, and S. Rowland, "Electric field analysis of $132 \mathrm{kv}$ epdm insulator and correlation with ageing features," in Electrical Insulation Conference (EIC), 2013 IEEE, pp. 210214, IEEE, 2013.

15. R. A. Rifai, A. H. Mansour, and M. A. H. Ahmed, "Estimation of the electric field and potential distribution on three dimension model of polymeric insulator using finite element method," 2015.

16. G. Vaillancourt, S. Carignan, and C. Jean, "Experience with the detection of faulty composite insulators on high-voltage power lines by the electric field measurement method," Power Delivery, IEEE Transactions on, vol. 13, no. 2, pp. 661-666, 1998.

17. S. Gubanski, A. Dernfalk, J. Andersson, and H. Hillborg, "Diagnostic methods for outdoor polymeric insulators," IEEE Transactions on Dielectrics and Electrical Insulation, vol. 5, no. 14, pp. 1065-1080, 2007.
18. J. M. Melenk and I. Babuška, "The partition of unity finite element method: basic theory and applications," Computer methods in applied mechanics and engineering, vol. 139, no. 1, pp. 289-314, 1996.

19. N. Sukumar, N. Moës, B. Moran, and T. Belytschko, "Extended finite element method for three-dimensional crack modelling," International Journal for Numerical Methods in Engineering, vol. 48, no. 11, pp. 1549-1570, 2000.

20. C. Wadhwa, High voltage engineering. New Age International, 2007.

21. D. K. Cheng, Field and wave electromagnetics, vol. 2. Addisonwesley New York, 1989.

22. V. Moreno and R. Gorur, "Effect of long-term corona on nonceramic outdoor insulator housing materials," Dielectrics and Electrical Insulation, IEEE Transactions on, vol. 8, no. 1, pp. 117128, 2001.

23. D. Williams, A. Haddad, A. Rowlands, H. Young, and R. Waters, "Formation and characterization of dry bands in clean fog on polluted insulators," Dielectrics and Electrical Insulation, IEEE Transactions on, vol. 6, no. 5, pp. 724-731, 1999.

24. S. G. M. Arshad, A. Nekahi and M. Farzaneh, "Influence of dry band width and location on flashover characteristics of silicone rubber insulators," IEEE Electrical Insulation Conference, Montreal, Canada, June 2016.

25. K. L. Chrzan and F. Moro, "Concentrated discharges and dry bands on polluted outdoor insulators," Power Delivery, IEEE Transactions on, vol. 22, no. 1, pp. 466-471, 2007.

26. M. S. Naidu and V. Kamaraju, High voltage engineering. Tata McGraw-Hill Education, 2013. 